Open Access

\title{
Type 2 diabetes mellitus worsens neurological injury following cardiac arrest: an animal experimental study
}

Lauge Vammen ${ }^{1,2}$, Søren Rahbek ${ }^{2}$, Niels Secher ${ }^{1}$, Jonas Agerlund Povlsen ${ }^{3}$, Niels Jessen ${ }^{4}$, Bo Løfgren ${ }^{2,3,5}$ and Asger Granfeldt ${ }^{*}$ (D)

* Correspondence: granfeldt@gmail.com 'Department of Intensive Care Medicine, Aarhus University Hospital, Aarhus, Denmark Full list of author information is available at the end of the article

\begin{abstract}
Background: Cardiac arrest carries a poor prognosis. The typical cardiac arrest patient is comorbid, and studies have shown that diabetes mellitus is an independent risk factor for increased mortality after cardiac arrest. Despite this, animal studies lack to investigate cardiac arrest in the setting of diabetes mellitus.

We hypothesize that type 2 diabetes mellitus in a rat model of cardiac arrest is associated with increased organ dysfunction when compared with non-diabetic rats.
\end{abstract}

Methods: Zucker diabetic fatty (ZDF) rats $(n=13)$, non-diabetic Zucker lean control (ZLC) rats $(n=15)$, and non-diabetic Sprague Dawley (SprD) rats $(n=8)$, underwent asphyxiainduced cardiac arrest. Animals were resuscitated and monitored for 180 min after return of spontaneous circulation (ROSC).

Blood levels of neuron-specific enolase were measured to assess neurological injury. Cardiac function was evaluated by echocardiography.

Results: No differences in cardiac output or neuron-specific enolase existed between the groups at baseline. Median levels of neuron-specific enolase $180 \mathrm{~min}$ after ROSC was $10.8 \mu \mathrm{g} / \mathrm{L}\left(\mathrm{Q}_{25} ; \mathrm{Q}_{75}-7.6 ; 11.3\right)$ in the ZDF group, which was significantly higher compared to the ZLC group at $2.0 \mu \mathrm{g} / \mathrm{L}\left(\mathrm{Q}_{25} ; \mathrm{Q}_{75}-1.7 ; 2.3, p<0.05\right)$ and the SprD group at $2.8 \mu \mathrm{g} / \mathrm{L}\left(\mathrm{Q}_{25} ; \mathrm{Q}_{75}-2.3 ; 3.4, p<0.05\right)$. At $180 \mathrm{~min}$ after $\mathrm{ROSC}$, cardiac output was $129 \mathrm{~mL} / \mathrm{min} / \mathrm{kg}$ (SD 45) in the ZDF group, which was not different from $106 \mathrm{~mL} / \mathrm{min} / \mathrm{kg}$ (SD 31) in the ZLC group or $123 \mathrm{~mL} / \mathrm{min} / \mathrm{kg}$ (SD 26, $p=0.72$ ) in the SprD group.

Conclusions: In a cardiac arrest model, neuronal injury is increased in type 2 diabetes mellitus animals compared with non-diabetic controls. Although this study lacks to uncover the specific mechanisms causing increased neuronal injury, the establishment of a cardiac arrest model of type 2 diabetes mellitus lays the important foundation for further experimental investigations within this field.

Keywords: Cardiac arrest, Resuscitation, Animal model, Type 2 diabetes mellitus, Neurological injury, Echocardiography 


\section{Background}

Cardiac arrest carries a poor prognosis. Organ injury following cardiac arrest is initiated by the ischemic insult and is paradoxically worsened by concomitant reperfusion, also known as ischemia-reperfusion (IR)-injury. In addition to systemic IR-injury, the post-cardiac arrest syndrome consists of myocardial dysfunction, brain injury, and the persisting precipitating pathology [1].

A precipitating pathology that may co-exist with cardiac arrest is type 2 diabetes mellitus (T2DM). Recent large clinical trials and retrospective studies have shown that the prevalence of diabetes mellitus is more frequent in cardiac arrest patients (13-28\%) [2-5] than in the background population (approx. 6\%) [6]. Following out-of-hospital cardiac arrest, patients with diabetes mellitus show reduced neurological recovery compared to non-diabetic patients [4, 7]. Importantly, several retrospective studies have demonstrated that diabetes mellitus independent of other risk factors is a strong predictor of poor outcome after cardiac arrest [8-11]. The exact mechanism behind this association is unknown. It may relate to augmented IR-injury which has been demonstrated in animal models of diabetes mellitus in organ-specific experiments [12-15]. However, in the setting of cardiac arrest, most experimental animal studies are conducted on healthy young animals [16], limiting our knowledge regarding the pathophysiology of the post-cardiac arrest syndrome and the impact of co-morbidities.

\section{Methods}

\section{Study aim}

The objectives of this study were to (1) establish a cardiac arrest animal model of T2DM and (2) to investigate the effect of T2DM on organ dysfunction following cardiac arrest. We hypothesize that T2DM is associated with increased neurological injury and cardiac dysfunction.

\section{Experimental animals and housing}

Three different groups of animals were used in the current study: (1) 16-18-week-old male Zucker diabetic fatty (ZDF) rats (fa/fa), (2) 16-18-week-old male Zucker lean control (ZLC) rats $(\mathrm{fa} /+)$ (Charles River Laboratories, Kingston, NY, USA), and age-matched male Sprague Dawley rats (SprD) (Janvier Labs, Le Genest-Saint-Isle, France). Both ZDF and ZLC rats originate from the same inbred strain of rats and shares an identical genetic background apart from a genetic mutation in the leptin receptor and defect in pancreatic $\beta$-cell transcription in the ZDF rats. [17].

During the pilot studies, a low rate of return of spontaneous circulation (ROSC) was observed in the ZLC group compared to ZDF animals. The SprD group was included to ensure a sufficiently powered healthy control group in case of a continued low ROSC rate in the ZLC group during the experiments. All animals were housed in pairs at standard room temperature, with a 12-h light/12-h dark cycle with free access to food and water. ZDF and ZLC rats were fed high-fat diet (Purina \#5008, LabDiet, St. Louis, MO, USA) as recommended by the supplier, while SprD rats were fed standard rodent diet (Altromin 1324, Lage, Germany). 


\section{Study design}

Animals underwent asphyxia-induced cardiac arrest in a randomized order with regard to the group by drawing pieces of paper from an envelope. Phenotypical differences made it impossible to blind the investigator to the experimental groups during experiments. The ischemic insult during asphyxial cardiac arrest consists of time to cardiac arrest and no-flow time. Based on the pilot experiments, the no-flow time in the ZDF and ZLC rats was set to $6.5 \mathrm{~min}$. Similarly, we experienced that time to cardiac arrest was of shorter duration in the SprD group compared with the two other groups. Consequently, the no-flow time in this group was extended to $8 \mathrm{~min}$ to have comparable total asphyxia times between SprD and ZDF groups (see Fig. 1).

\section{Diabetes diagnosis}

Animals were fasted for $5 \mathrm{~h}$ the day prior to cardiac arrest. To confirm diabetes, three tail capillary blood samples were collected, and blood glucose levels were measured (OneTouch UltraEasy Glucometer, Roche Diagnostics, Copenhagen, Denmark). Diabetes was defined as an average fasting blood glucose level $>7.0 \mathrm{mmol} / \mathrm{L}$.

\section{Animal and surgical preparation}

On the day of surgery, anesthesia was induced by $8 \%$ sevoflurane (Sevorane, AbbVie, Copenhagen, Denmark) in a chamber and maintained by $4 \%$ sevoflurane after intubation. The ventilator (MRI-1 ventilator, CWE Inc., PA, USA) was set to a tidal volume of $9 \mathrm{~mL} / \mathrm{kg}$ with $1 \mathrm{~cm}$ positive end-expiratory pressure and fraction of inspired oxygen $\left(\mathrm{FiO}_{2}\right)$ at $30 \%$. Respiratory rate was adjusted to maintain arterial partial pressure of $\mathrm{CO}_{2}\left(\mathrm{PaCO}_{2}\right)$ between 4.7 and $6.0 \mathrm{kPa}$. The left femoral artery and vein were catheterized using polyethylene tubing (PE 90 and PE 50, Intramedic ${ }^{\mathrm{Tx}}$, Copenhagen, Denmark), while mikro-tip catheters (Millar Instruments, TX, USA) were introduced into the right common carotid artery to the aortic root and into the external jugular vein to the right atrium. To prevent dehydration and clotting of catheters, $1 \mathrm{~mL} / \mathrm{kg}$ of heparinized saline

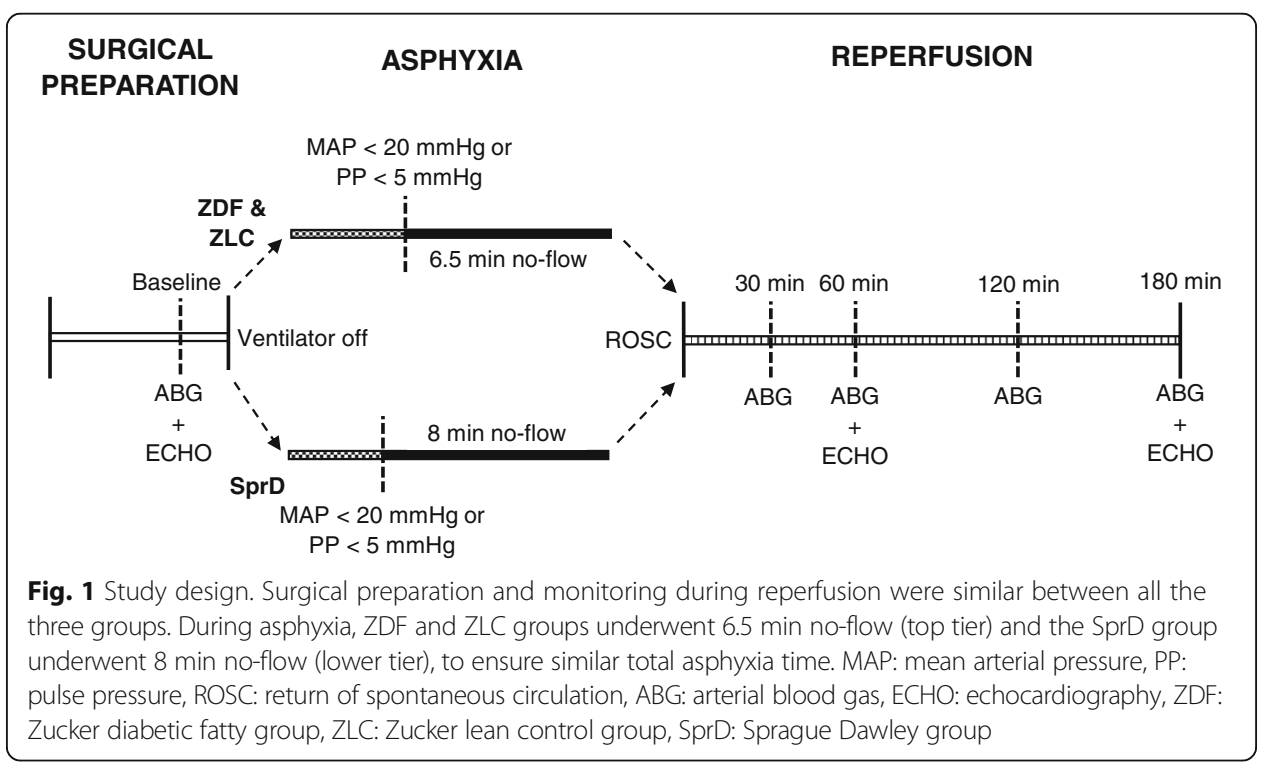


(2.5 IU/mL; Heparin, LEO Pharma, Malmö, Sweden) was administered every 30 min before cardiac arrest.

\section{Experimental protocol}

To inhibit spontaneous respiration during induction of cardiac arrest, $2.4 \mathrm{mg} / \mathrm{kg}$ rocuronium (Hameln Pharma plus, Hameln, Germany) was administered intravenously as a bolus before cardiac arrest. Immediately after the administration of rocuronium, both sevoflurane and positive end-expiratory pressure were discontinued. After a 30-s washout period, the ventilator was turned off and the inspiratory tube clamped. Cardiac arrest was defined as a mean arterial pressure (MAP) below $20 \mathrm{mmHg}$ and/or a pulse pressure lower than $5 \mathrm{mmHg}$.

Resuscitation was initiated with adrenaline $(0.01 \mathrm{mg} / \mathrm{kg})$, mechanical chest compressions by a custom-made thumper (set to $200 \mathrm{bpm}$ and a depth of one third of the height of the thorax), and ventilation with a respiratory rate of $110 \mathrm{~min}^{-1}$ and $\mathrm{FiO}_{2}$ of $100 \%$. Resuscitation was continued for up to 5 cycles of $2 \mathrm{~min}$ with heart rhythm analysis between cycles, followed by adrenaline administration. If a shockable rhythm occurred, up to three stacked shocks $(4 \mathrm{~J})$ were delivered through electrocardiogram electrodes placed on the front and back of the thorax. If a shockable rhythm was present at subsequent rhythm analyses, another shock was delivered. Chest compressions were resumed if conversion to a perfusing rhythm failed and/or a MAP below $40 \mathrm{mmHg}$ persisted.

Successful resuscitation was defined as MAP above $40 \mathrm{mmHg}$. Immediately after ROSC, sevoflurane was reinitiated at $2 \%$ for the remainder of the experiment. If the MAP dropped below $40 \mathrm{mmHg}$ following ROSC during the first $30 \mathrm{~min}$ after ROSC, adrenaline support $(0.0015 \mathrm{mg} / \mathrm{kg})$ was given. All animals were monitored for $180 \mathrm{~min}$ after ROSC. During monitoring, $\mathrm{FiO}_{2}$ was adjusted to maintain arterial oxygen saturation above $94 \%$. After resuscitation, to prevent dehydration, ZLC and SprD rats received $1 \mathrm{~mL} / \mathrm{kg}$ of heparinized saline every $2 \mathrm{~h}$, while the ZDF rats received the same dose every hour due to glycosuria and increased urine output. Seizures during the reperfusion period were defined as visible generalized tonic-clonic muscle contractions.

\section{Monitoring}

All animals were monitored with hind limb saturation, one-lead electrocardiogram, blood pressure, and heart rate during the entire experiment. The temperature was measured by a rectal probe and was kept at $37 \pm 0.5{ }^{\circ} \mathrm{C}$ during the entire experimental protocol. Blood gasses ( $45 \mu \mathrm{L}$ per sample) were collected from the femoral arterial catheter and analyzed (ABL 90 Flex Plus, Radiometer, Copenhagen, Denmark) at baseline, 30, 60, 120, and $180 \mathrm{~min}$ after ROSC. The coronary perfusion pressure (CPP) was calculated during resuscitation, as the difference between end-diastolic aortic and right atrial pressure measured by the mikro-tip catheters, as the average of five compressions, $20 \mathrm{~s}$ after the start of cardio-pulmonary resuscitation.

\section{Biochemistry}

Blood samples were drawn at baseline and at the end of the experiment; serum samples $(1 \mathrm{~mL})$ to measure neuron-specific enolase (NSE) and EDTA samples $(0.75 \mathrm{~mL})$ to 
measure troponin $\mathrm{T}$ (TnT), inflammatory cytokines (IL-1 $\beta$, IL-6, and IL-10), and adhesion molecules (soluble L-selectin [sL-selectin] and soluble ICAM-1 [sICAM-1]). The serum samples clotted for 20-30 min at room temperature before they were centrifuged at $4{ }^{\circ} \mathrm{C}$ and $1850 \mathrm{~g}$ for $9 \mathrm{~min}$, while the EDTA samples were centrifuged immediately at $4{ }^{\circ} \mathrm{C}$ and $1500 \mathrm{~g}$ for $20 \mathrm{~min}$. The supernatant was kept at $-80{ }^{\circ} \mathrm{C}$ before later analysis. NSE and TnT were analyzed on Cobas 6000 e601 (Roche Diagnostics, Copenhagen, Denmark). Inflammatory cytokines and adhesion molecules were analyzed using a multiplex assay (R\&D Systems Europe, Abingdon, UK). The assay was analyzed on a Luminex 100 using the BioPlex Software Manager 5.0 (Bio-Rad, Hercules, CA, USA). For all tests, a single analysis was made, and the investigator was blinded to both experimental group and examination time. Detection limits and intra-assay variation coefficients were as follows: NSE-0.05 $\mu \mathrm{g} / \mathrm{L}, 1.2 \%$; TnT-5 $\mathrm{ng} / \mathrm{L}, 1.7 \%$; IL-1 $\beta-32.3 \mathrm{pg} / \mathrm{mL}, 6.9 \%$; IL-6-384.9 pg/mL, 7.9\%; IL-10-22.9 pg/mL, 5.8\%; sL-selectin-206 pg/mL, 7.4\%; and sICAM-1-33.7 $\mathrm{pg} / \mathrm{mL}, 6.5 \%$.

\section{Echocardiography}

Echocardiographic examinations were performed at baseline, 60 and $180 \mathrm{~min}$ after ROSC (see Fig. 1). A stabilization period was allowed for baseline recordings between surgical preparations and cardiac arrest. Transthoracic 2D echocardiography of the left ventricle was performed with a GE Healthcare Vivid S6 ultrasound system using an $11-\mathrm{MHz}$ probe (12S-RS, GE Healthcare, Copenhagen, Denmark). All image analyses were performed after the experiments (EchoPac, GE Healthcare, Copenhagen, Denmark), randomized and blinded with regard to both experimental group and examination time. In the apical five-chamber view, pulsed waved Doppler was applied to measure the aortic outflow, and from this, the velocity time integral and heart rate were measured for three consecutive cardiac cycles. The left ventricular outflow tract (LVOT) diameter was measured in the parasternal long axis view, and from this, the LVOT area was calculated. Cardiac output $(\mathrm{mL} / \mathrm{min})$ was manually calculated and standardized to individual animal weight using the following formula: (LVOT-area in $\mathrm{cm}^{2} \times$ LVOT-VTI mean in $\mathrm{cm} \times$ heart frequency per $\mathrm{min}$ )/animal weight in $\mathrm{kg}$. In the parasternal short axis view (below mitral leaflets with visible papillary muscles), M-mode analysis was applied to evaluate the left ventricle during both diastole and systole for three consecutive cardiac cycles. The following dimensions were measured: interventricular septum thickness during both diastole (IVSD) and systole (IVSS), left ventricular inner diameter (LVIDD and LVIDS), and left ventricular posterior wall thickness (LVPWD and LVPWS). Left ventricular function was furthermore evaluated by fractional shortening: ((LVIDD - LVIDS)/LVIDD) $\times 100 \%$. To evaluate diastolic function, pulsed waved Doppler was applied in the apical four-chamber view to measure the mitral valve inflow, with subsequent analysis of $\mathrm{E} / \mathrm{A}$ ratio as an average over five cardiac cycles.

To determine intraobserver variability, 20 randomly selected images for each analysis were re-analyzed. The mean difference and 95\% confidence limits were $3.87 \mathrm{~mL} / \mathrm{min} /$ $\mathrm{kg}(-8.08 ; 15.83)$ for cardiac output from velocity time integral, $0.15 \%(-5.96 ; 5.67)$ for fractional shortening, and $0.01(-0.19 ; 0.21)$ for E/A ratio. 


\section{Statistical analysis}

Normally distributed data are presented as mean and standard deviation (SD), and non-normally distributed data are presented as median with associated $25 \%$ and $75 \%$ quartiles $\left(\mathrm{Q}_{25}\right.$ and $\left.\mathrm{Q}_{75}\right)$. Normality was determined by histograms and Q-Q plots. It was a priori determined that all comparisons are made between ZDF and ZLC rats or ZDF and SprD rats. No comparison between the control groups was performed. Due to the low number of animals with echocardiographic parameters in the ZLC group, echocardiographic parameters were only compared between the ZDF and SprD groups. Non-normally distributed data were transformed on a logarithmic scale to assume normality if possible, but all data in figures and tables are presented on the original scale. Repeated measurements were analyzed by repeated measurements analysis of variance (ANOVA) to detect difference over time between the groups. Baseline and end-of-experiment between-group differences were analyzed using Student's $t$ test or Mann-Whitney $U$ test as appropriate. Continuous variables were analyzed using Student's $t$ test or Mann-Whitney $U$ test. Dichotomous outcomes were compared using Fischer's exact test.

Analyses and figures were performed using Stata 12.1 (StataCorp, College Station, TX, USA) and Prism 6.07 (GraphPad, La Jolla, CA, USA). A p value below 0.05 was considered significant.

\section{Results}

A total of 40 animals were included in this study. Four animals were excluded: two ZDF rats due to technical difficulties prior to arrest, one SprD rat due to breach of resuscitation protocol, and one SprD rat developed severe hypoglycemia after cardiac arrest. The remaining 36 animals were distributed as follows: (1) ZDF group ( $n=13)$, (2) ZLC group $(n=15)$ rats, and (3) SprD rats $(n=8)$. The mean weight was $422 \mathrm{~g}$ (SD 46) in ZDF group, $353 \mathrm{~g}(\mathrm{SD} 23, p<0.05)$ in the ZLC group, and $460 \mathrm{~g}$ (SD 29, $p=0.05)$ in the SprD group.

\section{Fasting blood glucose levels}

All ZDF rats developed diabetes (fasting blood glucose $>7 \mathrm{mmol} / \mathrm{L}$ ). Median fasting glucose levels were significantly higher in the ZDF group at $19.9 \mathrm{mmol} / \mathrm{L}\left(\mathrm{Q}_{25} ; \mathrm{Q}_{75}-\right.$ $19.4 ; 21.2)$ when compared with the ZLC group at $5.0 \mathrm{mmol} / \mathrm{L}\left(\mathrm{Q}_{25} ; \mathrm{Q}_{75}-4.7 ; 5.2, p<\right.$ $0.05)$ and SprD group at $5.1 \mathrm{mmol} / \mathrm{L}\left(\mathrm{Q}_{25} ; \mathrm{Q}_{75}-5.0 ; 5.3, p<0.05\right)$.

\section{Cardiac arrest and resuscitation}

Data on cardiac arrest and resuscitation are presented in Table 1. Time to cardiac arrest differed significantly between the groups with the longest duration in the ZDF group

Table 1 Cardiac arrest and resuscitation

\begin{tabular}{llllll}
\hline Group & Time to cardiac arrest (s) & Total asphyxia time $(\mathrm{s})$ & Time to ROSC (s) & ROSC $_{\text {rate }}^{\ddagger}$ & CPP $(\mathrm{mmHg})^{\S}$ \\
\hline ZDF & $249(24)$ & $639(24)$ & $42(38 ; 46)$ & $11 / 13$ & $33(14)$ \\
ZLC & $202(18)^{*}$ & $592(18)^{*}$ & $75(60 ; 224)$ & $6 / 15^{*}$ & $18(13)^{*}$ \\
SprD & $154(20)^{\dagger}$ & $634(20)$ & $52(39 ; 57)$ & $8 / 8$ & $20(11)^{\dagger}$
\end{tabular}

Data are presented as mean (SD) or median $\left(\mathrm{Q}_{25} ; \mathrm{Q}_{75}\right){ }^{*} p<0.05 \mathrm{ZDF}$ vs. ZLC. ${ }^{\dagger} p<0.05 \mathrm{ZDF}$ vs. SprD. ${ }^{\ddagger}$ Animals achieved $\mathrm{ROSC} /$ total number of animals in group. ${ }^{5} \mathrm{CPP} 20 \mathrm{~s}$ after the start of resuscitation. $S$ seconds, ROSC return of spontaneous circulation, CPP coronary perfusion pressure, ZDF Zucker diabetic fatty group, ZLC Zucker lean control group, SprD Sprague Dawley group 
when compared with both the ZLC group $(p<0.05)$ and the SprD group $(p<0.05)$. Because of a longer no-flow time in the SprD group, no difference in the total asphyxia time existed between the ZDF and SprD groups $(p=0.60)$; it was, however, significantly longer in the ZDF group when compared with the ZLC group $(p<0.05)$.

The rate of ROSC varied significantly between ZDF (11/13) and ZLC (6/15) animals ( $p$ $<0.05)$, but not between ZDF and SprD animals $(8 / 8, p=0.51)$. The CPP $20 \mathrm{~s}$ after the start of cardio-pulmonary resuscitation was significantly higher in the ZDF group compared with both control groups (ZLC $p<0.05$ and $\operatorname{SprD} p<0.05$ ). During resuscitation, one ZDF rat and two ZLC rats were defibrillated due to ventricular fibrillation, of which one from the ZLC group was successfully converted to sinus rhythm and survived throughout the experimental protocol. Three animals in total (all ZDF rats) received adrenaline support during the initial $30 \mathrm{~min}$ of reperfusion. This was not statistically significant when compared to control groups (ZLC $p=0.52$ or $\operatorname{SprD} p=0.23$ ).

\section{Physiology}

Physiologic parameters are presented in Table 2. The MAP was lower in the SprD group $(p<0.05)$ at baseline compared with the ZDF group. Within the first $120 \mathrm{~min}$ after ROSC, MAP was higher in the ZDF group compared with both control groups, but no significant difference was observed between the groups after $180 \mathrm{~min}$. At the end of the experiment, $\mathrm{pH}$ and base excess (BE) were significantly lower in the ZDF group compared with the ZLC group ( $p<0.05$ for both variables) and the SprD group ( $p<0.05$ for both variables). Higher potassium levels were also seen in the ZDF group compared with the ZLC group $(p<0.05)$ and SprD group $(p<0.05)$. After ROSC, lactate levels were elevated in the ZDF group. Furthermore, at the end of the experiment, lactate in the ZDF group was significantly higher than in the ZLC group $(p<0.05)$ and the SprD group $(p<0.05)$. Blood glucose levels were significantly higher in the ZDF group when compared with both the ZLC and SprD groups $\left(p<0.05\right.$ at baseline and end of the experiment for both groups). $\mathrm{PaO}_{2} /$ $\mathrm{FiO}_{2}$ levels were significantly lower in the ZDF group at baseline when compared to SprD rats with no difference between ZLC and ZDF groups. $\mathrm{PaO}_{2} / \mathrm{FiO}_{2}$ increased over time in the ZDF group and decreased in ZLC and SprD groups with significantly higher levels in the ZDF group at the end of the experiment.

\section{Neurological injury}

The serum values of NSE from all the three groups are displayed in Fig. 2a. No difference was observed between groups at baseline. At the end of the study, median NSE was $10.8 \mu \mathrm{g} / \mathrm{L}\left(\mathrm{Q}_{25} ; \mathrm{Q}_{75}-7.6 ; 11.3\right)$ in the ZDF group which was significantly higher compared to the ZLC group at $2.0 \mu \mathrm{g} / \mathrm{L}\left(\mathrm{Q}_{25} ; \mathrm{Q}_{75}-1.7 ; 2.3, p<0.05\right)$ and the SprD group at $2.8 \mu \mathrm{g} / \mathrm{L}$ $\left(\mathrm{Q}_{25} ; \mathrm{Q}_{75}-2.3 ; 3.4, p<0.05\right)$. Following cardiac arrest, all ZDF animals $(11 / 11)$ had seizures, which was significantly more frequent compared with $\operatorname{SprD}$ animals $(1 / 8, p<0.05)$. No significant difference was observed with regard to the ZLC animals $(4 / 6, p=0.11)$.

\section{Cardiac function}

At baseline, levels of TnT (Fig. 2b) were $28.1 \mathrm{ng} / \mathrm{L}$ (SD 25.7) in the ZDF group, $26.8 \mathrm{ng} / \mathrm{L}$ (SD13.3, $p=0.91$ ) in the ZLC group, and significantly lower in the SprD group at $9.9 \mathrm{ng} / \mathrm{L}$ (SD 5.3, $p<0.05)$. No statistical significant difference was 
Table 2 Mean arterial pressure, heart rate, temperature, and blood gas analysis

\begin{tabular}{|c|c|c|c|c|c|c|c|}
\hline & GROUP & Baseline & 30 min ROSC & 60 min ROSC & 120 min ROSC & 180 min ROSC & $p$-value \\
\hline \multirow[t]{3}{*}{ MAP, $\mathrm{mmHg}$} & ZDF & $103(15)$ & $107(41)$ & $95(32)$ & $97(27)$ & $53(20)$ & \\
\hline & ZLC & $98(11)$ & $97(41)$ & $47(7)$ & $52(7)$ & $55(14)$ & $<0.05$ \\
\hline & SprD & $77(10)^{\dagger}$ & $74(25)$ & $49(4)$ & $54(14)$ & $58(12)$ & $<0.05$ \\
\hline \multirow[t]{3}{*}{ Temp, ${ }^{\circ} \mathrm{C}$} & ZDF & $37.1(0.2)$ & $36.9(0.2)$ & $36.6(0.2)$ & $37.2(0.4)$ & $37.0(0.3)$ & \\
\hline & ZLC & $37.0(0.2)$ & $36.9(0.2)$ & $37.0(0.3)$ & $37.0(0.2)$ & $37.1(0.3)$ & $<0.05$ \\
\hline & SprD & $37.0(0.1)$ & $36.9(0.1)$ & $36.9(0.2)$ & $37.1(0.1)$ & $37.1(0.2)$ & 0.07 \\
\hline \multirow[t]{3}{*}{$\mathrm{pH}$} & ZDF & $7.47(0.05)$ & 7.30 (0.09) & $7.32(0.08)$ & $7.19(0.07)$ & $7.11(0.10)$ & \\
\hline & ZLC & $7.46(0.05)$ & $7.31(0.06)$ & $7.32(0.05)$ & $7.32(0.03)$ & $7.32(0.03)^{*}$ & $<0.05$ \\
\hline & SprD & $7.49(0.02)$ & $7.34(0.06)$ & $7.37(0.05)$ & $7.39(0.04)$ & $7.38(0.05)^{\dagger}$ & $<0.05$ \\
\hline \multirow[t]{3}{*}{$\mathrm{BE}, \mathrm{mmol} / \mathrm{L}$} & ZDF & $5.0(3.7)$ & $-7.9(3.4)$ & $-6.4(3.1)$ & $-12.9(4.0)$ & $-17.5(5.1)$ & \\
\hline & ZLC & $4.0(3.4)$ & $-5.4(3.3)$ & $-4.5(3.5)$ & $-3.4(3.6)$ & $-4.4(2.9)^{*}$ & $<0.05$ \\
\hline & SprD & 5.9 (1.6) & $-3.4(2.3)$ & $-1.0(1.8)$ & $-0.4(1.7)$ & $-1.3(3.2)^{\dagger}$ & $<0.05$ \\
\hline \multirow[t]{3}{*}{$\mathrm{PaCO} 2, \mathrm{kPa}$} & ZDF & $5.3(0.6)$ & $5.0(1.6)$ & $5.1(0.7)$ & $5.2(0.6)$ & $4.9(0.9)$ & \\
\hline & ZLC & $5.2(0.3)$ & $5.6(1.2)$ & $5.6(1.0)$ & $5.9(0.6)$ & $5.6(0.4)$ & 0.64 \\
\hline & SprD & $5.1(0.1)$ & $5.5(0.7)$ & $5.7(0.7)$ & $5.5(0.6)$ & $5.3(0.2)$ & 0.47 \\
\hline \multirow[t]{3}{*}{$\mathrm{PaO} 2 / \mathrm{FiO} 2$ ratio } & ZDF & $450(518)$ & $450(270)$ & 398 (255) & $570(323)$ & $636(368)$ & \\
\hline & ZLC & $518(105)$ & $270(120)$ & $255(75)$ & $323(143)$ & $368(128)^{*}$ & $<0.05$ \\
\hline & SprD & $563(68)^{\dagger}$ & $315(143)$ & $330(120)$ & $368(83)$ & $435(150)^{\dagger}$ & $<0.05$ \\
\hline \multirow[t]{3}{*}{ Glucose, $\mathrm{mmol} / \mathrm{L}$} & ZDF & $25.9(6.2)$ & $39.5(8.0)$ & $39.5(8.1)$ & $41.9(5.9)$ & $43.9(4.3)$ & \\
\hline & ZLC & $11.9(2.2)^{*}$ & $12.8(2.7)$ & $9.8(3.6)$ & $7.4(1.5)$ & $5.4(1.2)^{*}$ & $<0.05$ \\
\hline & SprD & $11.6(0.8)^{\dagger}$ & $11.1(0.8)$ & $8.2(0.8)$ & $7.7(0.5)$ & $6.8(2.1)^{\dagger}$ & $<0.05$ \\
\hline \multirow[t]{3}{*}{ Lactate, mmol/L } & ZDF & $2.2(1.1)$ & $6.4(2.4)$ & $5.0(1.7)$ & $7.4(3.3)$ & $8.2(3.1)$ & \\
\hline & ZLC & $1.2(0.4)$ & $4.1(1.2)$ & $3.1(1.5)$ & $2.6(1.7)$ & $2.6(1.7)^{*}$ & $<0.05$ \\
\hline & SprD & $1.2(0.5)$ & $3.9(0.9)$ & $2.7(0.7)$ & $2.1(0.8)$ & $1.8(0.9)^{\dagger}$ & $<0.05$ \\
\hline \multirow[t]{3}{*}{$\mathrm{K}^{+}, \mathrm{mmol} / \mathrm{L}$} & ZDF & $4.0(0.3)$ & $5.4(0.7)$ & $6.1(1.6)$ & $6.4(0.9)$ & $7.9(1.5)$ & \\
\hline & ZLC & $4.1(0.4)$ & $3.9(0.4)$ & $4.9(1.0)$ & $5.6(0.8)$ & $5.6(0.5)^{*}$ & $<0.05$ \\
\hline & SprD & $4.7(0.3)^{\dagger}$ & $4.3(0.3)$ & $5.4(0.4)$ & $6.0(0.4)$ & $5.6(0.9)^{\dagger}$ & $<0.05$ \\
\hline
\end{tabular}

All data are presented as mean (SD). ${ }^{*} p<0.05$ ZDF vs. ZLC at baseline or 180 min after $\mathrm{ROSC} .{ }^{\dagger} p<0.05$ ZDF vs. SprD at baseline or $180 \mathrm{~min}$ after ROSC. ${ }^{\ddagger}$ Time/group interaction (rep. meas. ANOVA), ZDF vs. ZLC and ZDF vs. SprD. ROSC return of spontaneous circulation, MAP mean arterial pressure, $B E$ base excess, $\mathrm{PaCO} 2 \mathrm{CO}_{2}$ in arterial blood, $\mathrm{PaO} 2 \mathrm{O}_{2}$ in arterial blood, $\mathrm{FiO} 2$ fraction of $\mathrm{O} 2$ in inspiratory air, $\mathrm{K}^{+}$potassium, ZDF Zucker diabetic fatty group, ZLC Zucker lean control group, SprD Sprague Dawley group

observed $180 \mathrm{~min}$ after ROSC between ZDF and ZLC groups $(p=0.48)$ or ZDF and SprD groups $(p=0.11)$.

Cardiac output standardized to weight (Fig. 3a) was not statistically different between ZDF and SprD groups at baseline $(p=0.47)$ or at $180 \mathrm{~min}$ after $\operatorname{ROSC}(p=0.72)$.

No difference was observed between ZDF and SprD groups in fractional shortening at baseline (Fig. 3b). At the end of the experiment, fractional shortening was 36\% (SD 6) in ZDF group, which was significantly higher than $24 \%$ (SD 6, $p<0.05$ ) in the SprD group. No differences in E/A ratio were observed between the groups throughout the experimental period (Fig. 3c). The left ventricular dimensions (Fig. 4a-f) were similar at baseline between ZDF and SprD groups. At 180 min after ROSC, however, the IVS and LVPW was statistically significantly thicker, and LVID statistically significantly smaller in the ZDF group compared with the SprD group. This was true during both diastole and systole. 

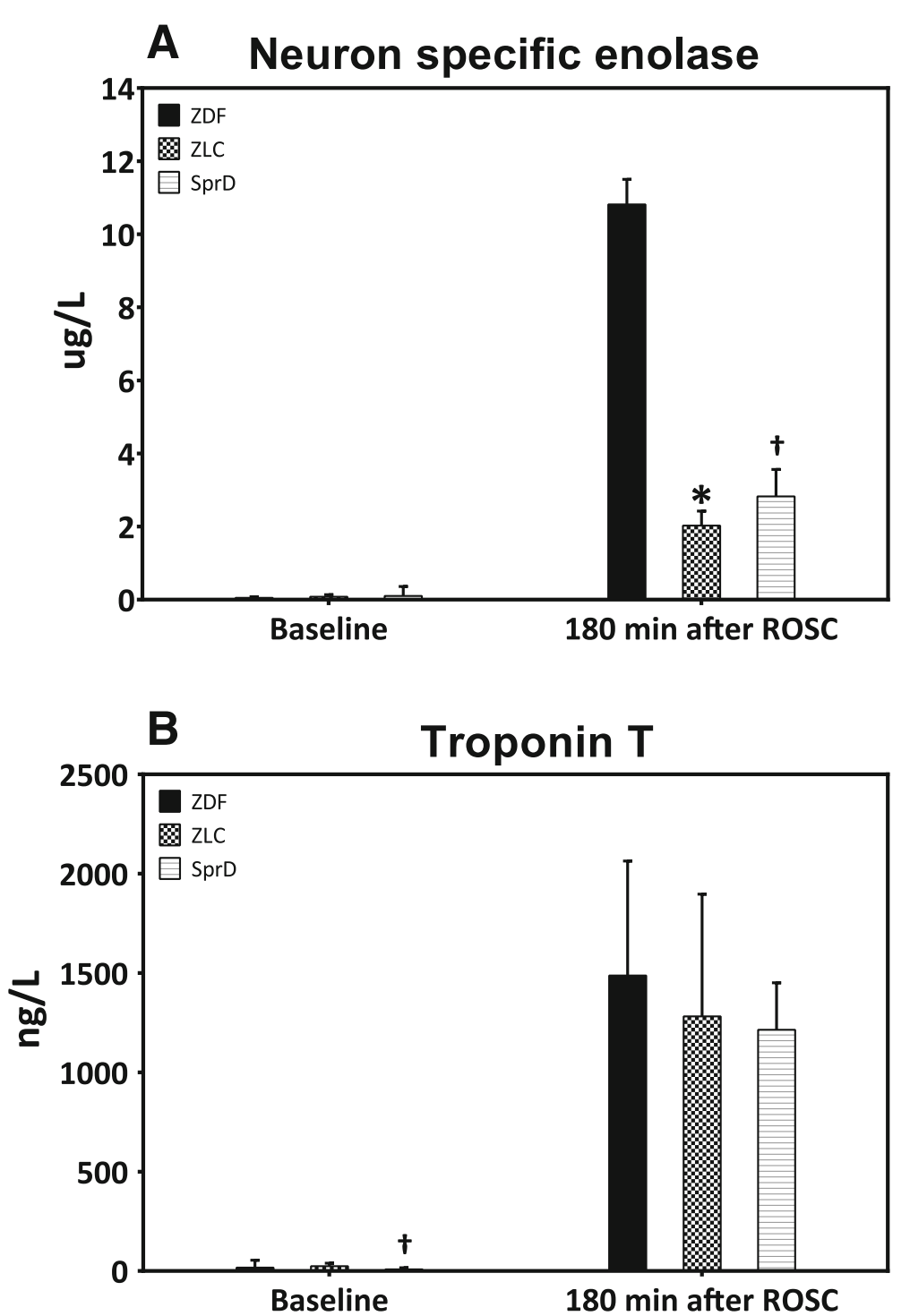

Fig. 2 Neuron-specific enolase and troponin T. a Neuron-specific enolase values at baseline and $180 \mathrm{~min}$ after ROSC. Data are presented as median and associated quartiles $\left(\mathrm{Q}_{25}\right.$ and $\left.\mathrm{Q}_{75}\right)$. Number of animals: ZDF $(n=10)$, ZLC $(n=6)$, and SprD $(n=8)$. b Troponin T values at baseline and $180 \mathrm{~min}$ after ROSC. Data are presented as mean and SD. Number of animals: ZDF ( $n=11$, one missing data point at 180 min after ROSC), ZLC $(n=6)$, and SprD $(n=8)$. For both analyses, only the animals achieving ROSC are included. ${ }^{*} p<0.05$ ZDF vs. ZLC; ${ }^{+} p<0.05$ ZDF vs. SprD. ROSC: return of spontaneous circulation, ZDF: Zucker diabetic fatty group, ZLC: Zucker lean control group, SprD: Sprague Dawley group

\section{Inflammatory cytokines and adhesion molecules}

Figure 5 shows the levels of cytokines and soluble endothelial adhesion molecules in the plasma. No difference in the cytokines was observed at baseline between the groups. All cytokine levels increased following ROSC. At the end of the experiment, the ZLC group had significantly lower levels of IL-1 $\beta$, IL-6, and IL-10 compared with the ZDF group ( $p<0.05$ for all three cytokines), and the SprD group had significantly lower levels of IL-6 and IL-10 compared to the ZDF group ( $p<0.05$ for both cytokines). Both sICAM-1 and sL-selectin levels increased in all the three groups $180 \mathrm{~min}$ after ROSC. At baseline, sICAM-1 concentrations were higher in the ZDF group compared 


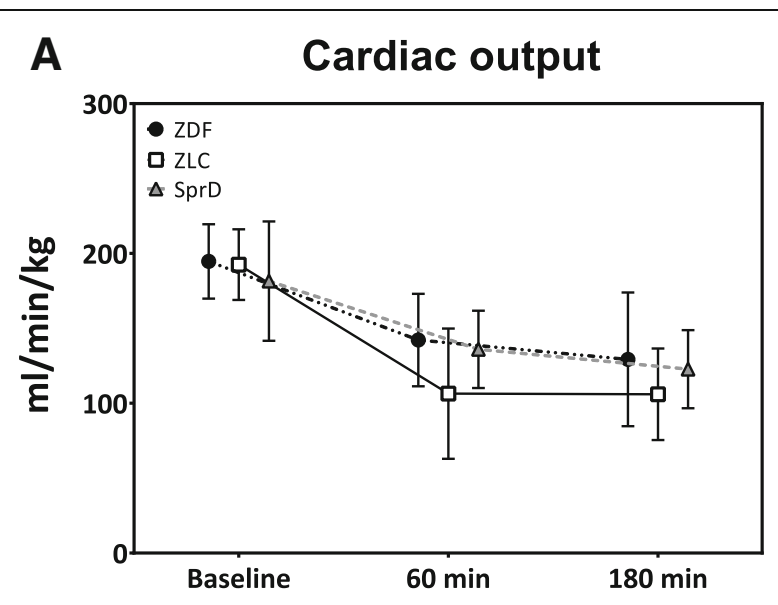

B Fractional shortening
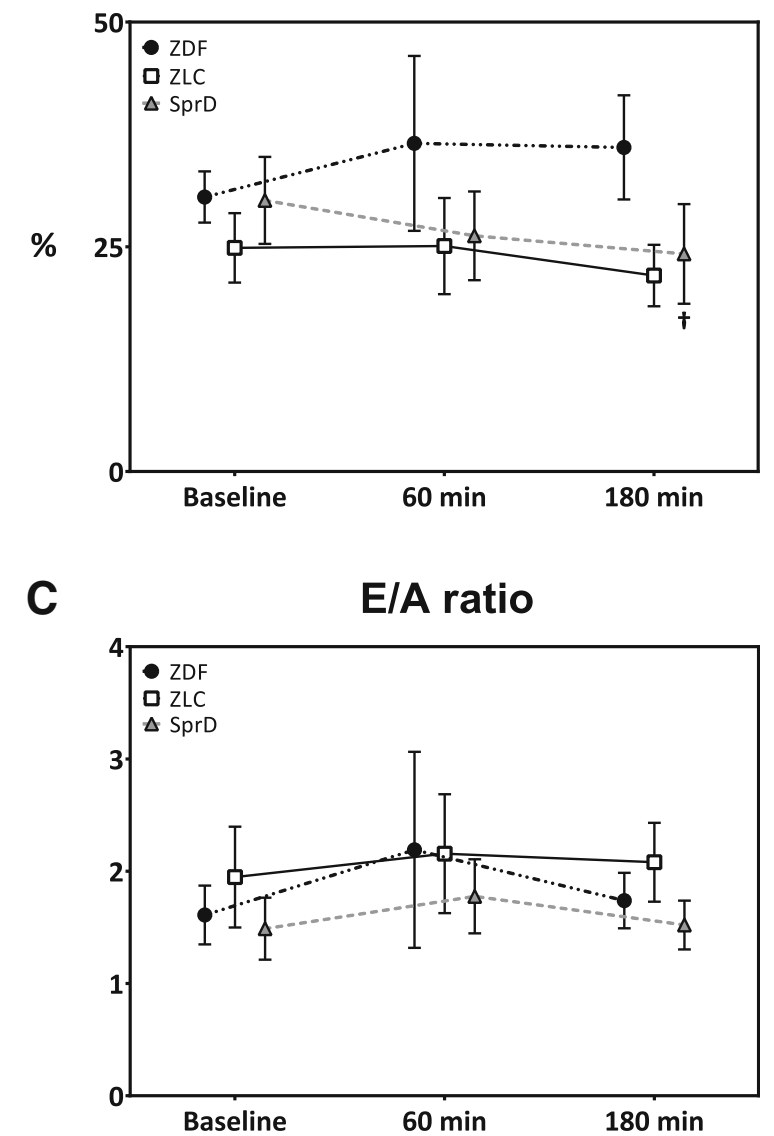

Fig. 3 Echocardiographic parameters of cardiac function. Data are presented as mean and SD. a Cardiac output standardized to animal weight. Number of animals at examination times: $\operatorname{ZDF}(n=13,11$, and 9), ZLC ( $n=10,5$, and 2), and SprD ( $n=8$ at all examinations). b Fractional shortening; ZDF $(n=11,11$, and 10), ZLC $(n=14,6$, and 5), and SprD ( $n=8$ at all examinations). c E/A ratio; ZDF ( $n=12,10$, and 8$)$, ZLC $(n=14$, 5, and 4), and SprD ( $n=8,6$, and 8). ${ }^{+} p<0.05$ ZDF vs. SprD. ZDF: Zucker diabetic fatty group, ZLC: Zucker lean control group, SprD: Sprague Dawley group

with the ZLC group $(p<0.05)$. No difference was seen at the end of the experiment. In the SprD group, sL-selectin was higher both at baseline $(p<0.05)$ and $180 \mathrm{~min}$ after ROSC $(p<0.05)$ compared with the ZDF group. 


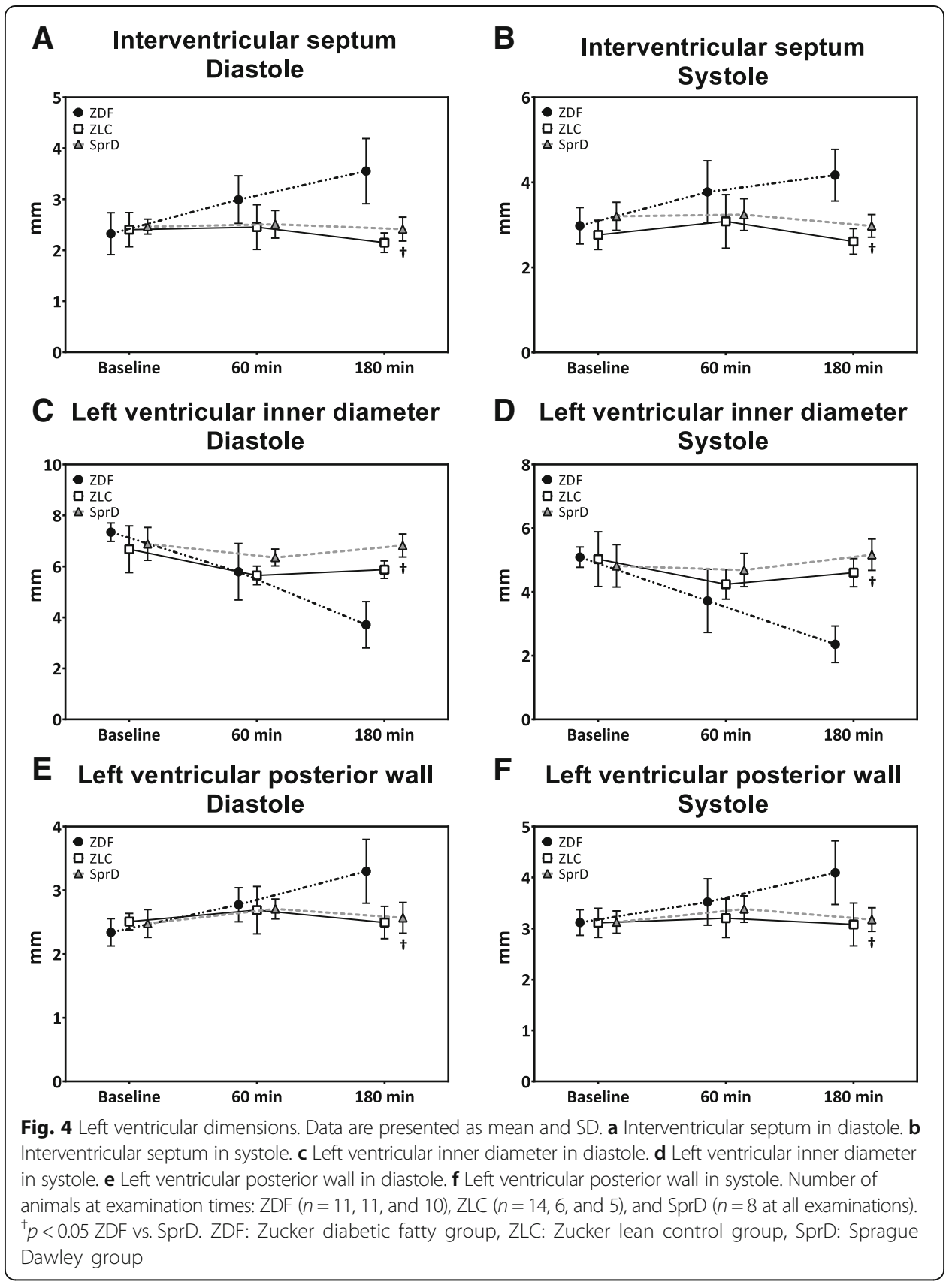

\section{Discussion}

In the current study, we demonstrate that animals with T2DM compared with both groups of non-diabetic animals namely ZLC and SprD rats have more severe neurological injury following cardiac arrest, higher cytokine levels, and generalized metabolic derangement.

\section{Neurological injury}

A major finding in the current study is the indication of increased neurological injury, observed in the ZDF group as higher levels of NSE. This observation may relate to the 


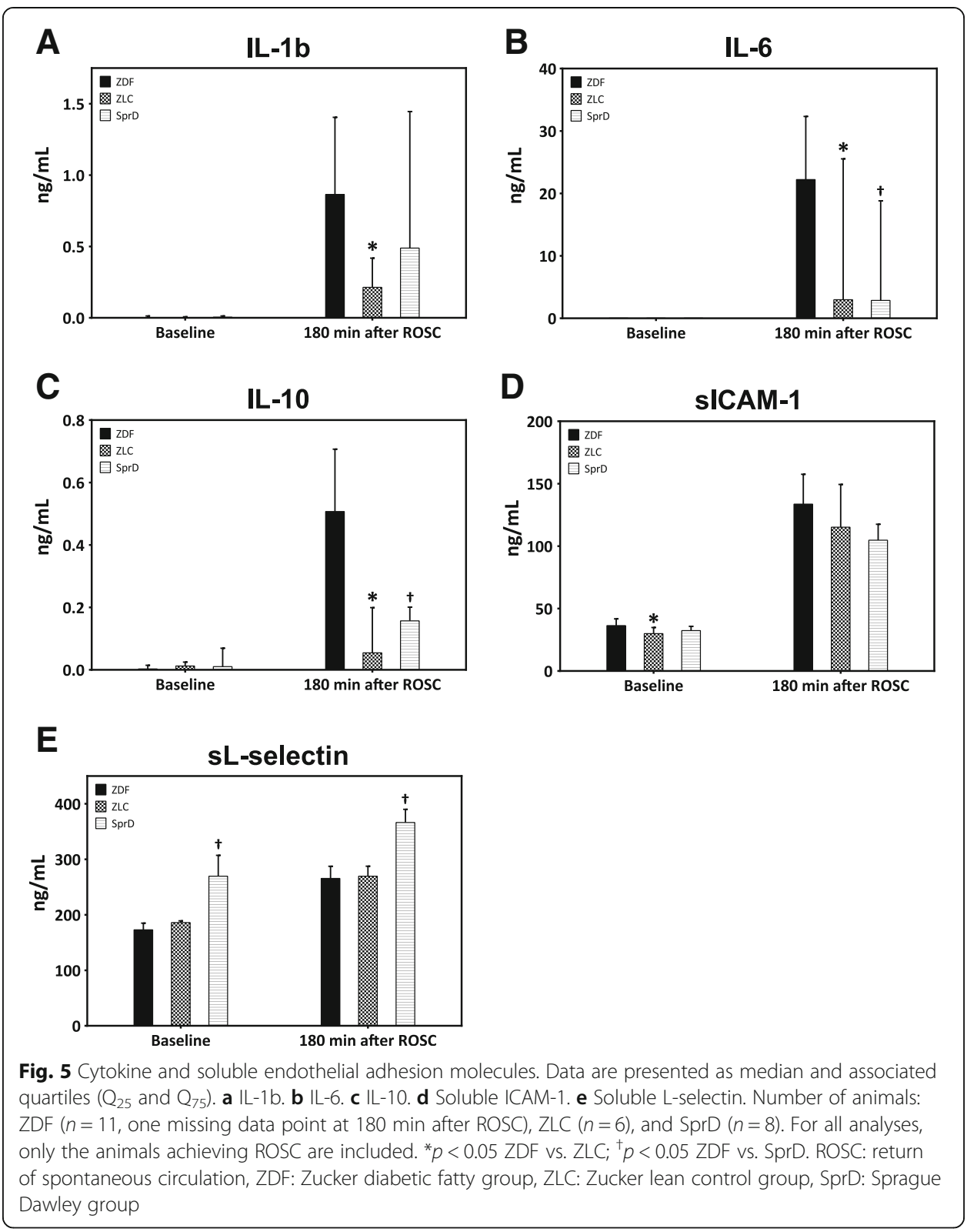

high glucose levels observed following cardiac arrest in the ZDF group. Hyperglycemia after cardiac arrest has been linked with poor neurological outcome in both experimental and human studies [18-21]; however, it is unclear whether this is caused by direct neurological injury, cardiovascular failure, or other pathologic processes. A direct effect on neurological injury is supported by a meta-analysis including animal models of the middle cerebral artery occlusion that showed increased cerebral infarct size in dextrose induced hyperglycemic animals [22]. In contrast, Nehme et al. [4] have in a retrospective study shown that mild pre-hospital hyperglycemia $(8.0-11.9 \mathrm{mmol} / \mathrm{L})$ independent of diabetes following out-of-hospital cardiac arrest may increase survival to hospital discharge. If diabetic animals were treated with glucose-lowering drugs, it might have been possible to avoid the detrimental effects of hyperglycemia. We refrained from administering glucose-lowering drugs to minimize differences between the groups, as 
most conventional glucose-lowering treatments have shown independent protective properties in the setting of IR-injury [23]. Elevated NSE levels are the major indicator of increased brain damage in the ZDF rats; however, little is known about NSE levels during the acute phase (within hours) of the post-cardiac arrest syndrome in humans [24]. Kang et al. [25] showed NSE levels of $2.9 \mu \mathrm{g} / \mathrm{L}$ and $4.5 \mu \mathrm{g} / \mathrm{L}$ after 1 and $6 \mathrm{~h}$ of reperfusion in non-diabetic rats following $5 \mathrm{~min}$ of cardiac arrest, which is similar to what we observed in the SprD group. Neurological function in the current study was only evaluated by NSE levels and visible generalized tonic-clonic muscle contractions, which may be considered as a potential limitation. Notably, studies have shown association between neuronal injury examined by histology, neuro-functional tests, and NSE levels [26-29].

\section{Cardiac function}

The cardiac function parameters were ambiguous, and due to the low number of animals with echocardiographic parameters in the ZLC group, the data must be interpreted with caution. We saw no difference in the cardiac output between ZDF and SprD groups; TnT values were highest in the ZDF group although not significantly, whereas, fractional shortening suggested increased left ventricular function in the diabetic group at the end of the experiment. However, fractional shortening may be an inadequate measure of cardiac function in this study as the decreased LVID and concomitant increased IVS and LPW thickness in the ZDF group may potentially result in an increased fractional shortening even in the presence of an unaltered or perhaps lowered stroke volume. This is supported by our finding of no difference in the cardiac output after cardiac arrest in the ZDF and SprD groups. The decreased diastolic diameter and increased wall thicknesses in the ZDF group may reflect edema and ischemic contracture due to IR-injury. This is supported by higher levels of TnT in the ZDF group although not significant. While previous studies in chronic diabetic rats have shown increased susceptibility to IR-injury [12, 30], this depends among other aspects on the age of the included animals as studies in isolated perfused hearts have shown increased hemodynamic recovery in 12-16-week-old ZDF rats, when compared with non-diabetic controls [31,32]. Considering this, the increased fractional shortening in the ZDF group could be explained by this as our rats were 16-18 weeks old. We chose this age span to ensure that the induction of cardiac arrest was conducted on animals with fully developed T2DM, which were still resilient enough to survive the systemic IR-injury.

\section{Inflammatory response}

The inflammatory response to resuscitation after cardiac arrest is complex, with an early activation of endothelial cells, cytokine response, and upregulation of adhesion molecules [33]. A pro-inflammatory response has been seen in patients with T2DM outside the setting of cardiac arrest, as several studies have shown, e.g., increased levels of IL-6 in T2DM patients [34-36]. It is therefore reasonable to believe that T2DM could affect the post-cardiac arrest inflammatory response. Interestingly, we showed no difference in cytokine levels between the groups prior to cardiac arrest. However, the higher cytokine plasma levels in the ZDF group following cardiac arrest could be a 
manifestation of increased IR-injury, as especially high plasma levels of IL-6 following the immediate phase after ROSC have been associated with cardiovascular dysfunction and a lower 30-day survival in humans [37, 38]. The high IL-10 levels might be a result of a preserved balance between the pro- and anti-inflammatory cytokines, as IL-10 is considered as one of the major anti-inflammatory cytokines [39]. Whether the elevated cytokine levels were due to a direct effect of diabetes on the inflammatory response elicited by IR-injury or other pathological process needs further investigations. Greater sICAM-1 levels in the ZDF vs. ZLC group at baseline is consistent with the previous literature [14]. Surprisingly, we saw higher sL-selectin levels in the SprD group. The fact that this was true both before and after cardiac arrest points in the direction of a between race difference in selectin expression.

\section{CPP and ROSC rates}

Although a significantly greater CPP was achieved during resuscitation in the ZDF group vs. the ZLC and SprD groups, the ROSC rate did only differ between the ZDF and ZLC group, being the lowest in the latter group. In humans, a CPP above $15 \mathrm{mmHg}$ is associated with an increased chance of achieving ROSC [40]. In our study, the mean values in all groups were above this limit, but one animal in the ZLC group achieved a substantially higher CPP, which could mask a trend of the overall lower perfusion pressures in this group. The study by Paradis et al. also indicates a correlation between increased maximum CPP values above $15 \mathrm{mmHg}$ and higher ROSC rates, which could explain the increased ROSC rate in the ZDF rats compared with ZLC rats. The mechanical chest compression device was adjusted within a narrow range for the compression depth to correspond to one third of the thorax height and do not give an apparent explanation for the differences in CPP. Whether the difference in ROSC rates is related to the presence of hyperglycemia during resuscitation or is caused by cardiovascular changes induced by T2DM remains speculative.

\section{Limitations}

The study has a number of limitations. The surprisingly low number of animals in the ZLC group achieving ROSC limits our ability to detect the differences between the groups following ROSC. Although total asphyxia times were similar between the SprD and ZDF rats, the no-flow time was increased in the SprD group making direct comparability difficult. The ZDF and ZLC rats are from the same inbred race of rats, opposed to the outbred and more genetic heterogenic SprD rat. This complicates the between-group comparison and may inflict unknown confounders to our results. The relative short reperfusion duration of $3 \mathrm{~h}$ limits the results to apply only to the acute setting of the post-cardiac arrest syndrome, which lasts multiple days in the clinical setting. Pilot studies showed that a longer reperfusion period was impossible due to premature death in the ZDF group. The limited blood volume of the rats precluded repeated blood samples and limited the number of biochemical analyses why we focused on neurological and cardiovascular function, as they are the most common causes of death following cardiac arrest [41]. Our results suggest a potential impact of T2DM on the 
post-cardiac arrest syndrome, but further studies are needed to investigate the mechanism behind IR-injury in the setting of T2DM.

\title{
Conclusions
}

In a cardiac arrest model, neuronal injury is increased in T2DM animals compared with non-diabetic controls. Although this study lacks to uncover the specific mechanisms causing increased neuronal injury, the establishment of a cardiac arrest model of T2DM lays the important foundation for further experimental investigations within this field.

\begin{abstract}
Abbreviations
BE: Base excess; CPP: Coronary perfusion pressure; $\mathrm{FiO}_{2}$ : Fraction of $\mathrm{O}_{2}$ in inspiratory air; IR-injury: Ischemia-reperfusion injury; IVSD: Interventricular septum in diastole; IVSS: Interventricular septum in systole; LVIDD: Left ventricular inner diameter in diastole; LVIDS: Left ventricular inner diameter in systole; LVOT: Left ventricular outflow tract; LVPWD: Left ventricular posterior wall in diastole; LVPWS: Left ventricular posterior wall in systole; MAP: Mean arterial pressure; NSE: Neuron-specific enolase; $\mathrm{PaCO}_{2}: \mathrm{CO}_{2}$ partial pressure in arterial blood; $\mathrm{PaO}_{2}: \mathrm{O}_{2}$ partial pressure in arterial blood; ROSC: Return of spontaneous circulation; SD: Standard deviation; SprD: Sprague Dawley; T2DM: Type 2 diabetes mellitus; ZDF: Zucker diabetic fatty; ZLC: Zucker lean control

\section{Funding}

This study was conducted with funding from Independent Research Fund Denmark, ZOLL Foundation, A.P. Møller Foundation, Eva and Hans Carl Adolf Holm's Memorial Scholarship, Oticon Foundation, and August Frederik Wedell Erichsen's Scholarship. None of the funding sources played any role in the design, data collection, analysis, interpretation, writing, or submission of the paper for publication.
\end{abstract}

\section{Availability of data and materials}

All datasets supporting the conclusions are available from the corresponding author on reasonable request.

\section{Authors' contributions}

NS, JP, NJ, BL, and AG contributed to the idea and design. LV and SR contributed to the animal model setup and pilot studies. LV contributed to the conduction of the experiments. NS and AG contributed to the data analysis. LV, SR, NS, $J P, N J, B L$, and AG contributed to the drafting and writing of the manuscript. All authors read and approved the final manuscript.

\section{Ethics approval}

The study was approved by the Danish Animal Experiments Inspectorate (License number: 2012-15-2934-00447) and conducted in accordance with the "Guide for the Care and Use of Laboratory Animals" (National Research Council (US) Committee for the Update of the Guide for the Care and Use of Laboratory Animals. Washington (DC), National Academies Press (US) 8th edition 2011).

\section{Consent for publication}

Not applicable.

\section{Competing interests}

The authors declare that they have no competing interests.

\section{Publisher's Note}

Springer Nature remains neutral with regard to jurisdictional claims in published maps and institutional affiliations.

\section{Author details}

${ }^{1}$ Department of Intensive Care Medicine, Aarhus University Hospital, Aarhus, Denmark. ${ }^{2}$ Research Center for Emergency Medicine, Aarhus University Hospital, Aarhus, Denmark. ${ }^{3}$ Department of Cardiology, Aarhus University Hospital, Aarhus, Denmark. ${ }^{4}$ Department of Clinical Pharmacology, Aarhus University, Aarhus, Denmark. ${ }^{5}$ Department of Internal Medicine, Regional Hospital of Randers, Randers, Denmark.

Received: 16 December 2017 Accepted: 30 July 2018

Published online: 07 August 2018

\section{References}

1. Neumar RW, Nolan JP, Adrie C, Aibiki M, Berg RA, Bottiger BW, Callaway C, Clark RS, Geocadin RG, Jauch EC, Kern KB, Laurent I, Longstreth WT Jr, Merchant RM, Morley P, Morrison LJ, Nadkarni V, Peberdy MA, Rivers EP, Rodriguez-Nunez A, Sellke FW, Spaulding C, Sunde K, Vanden Hoek T (2008) Post-cardiac arrest syndrome: epidemiology, pathophysiology, treatment, and prognostication. A consensus statement from the International Liaison Committee on Resuscitation (American Heart Association, Australian and New Zealand Council on Resuscitation, European Resuscitation Council, Heart and Stroke Foundation of Canada, InterAmerican Heart Foundation, Resuscitation Council of Asia, and the Resuscitation Council of Southern Africa); the American Heart 
Association Emergency Cardiovascular Care Committee; the Council on Cardiovascular Surgery and Anesthesia; the Council on Cardiopulmonary, Perioperative, and Critical Care; the Council on Clinical Cardiology; and the Stroke Council. Circulation 118:2452-2483.

2. Nielsen N, Wetterslev J, Cronberg T, Erlinge D, Gasche Y, Hassager C, Horn J, Hovdenes J, Kjaergaard J, Kuiper M, Pellis T, Stammet P, Wanscher M, Wise MP, Aneman A, Al-Subaie N, Boesgaard S, Bro-Jeppesen J, Brunetti I, Bugge JF, Hingston CD, Juffermans NP, Koopmans M, Kober L, Langorgen J, Lilja G, Moller JE, Rundgren M, Rylander C, Smid O, Werer C, Winkel P, Friberg H (2013) Targeted temperature management at 33 degrees C versus 36 degrees C after cardiac arrest. N Engl J Med 369:2197-2206.

3. Rubertsson S, Lindgren E, Smekal D, Ostlund O, Silfverstolpe J, Lichtveld RA, Boomars R, Ahlstedt B, Skoog G, Kastberg R, Halliwell D, Box M, Herlitz J, Karlsten R (2014) Mechanical chest compressions and simultaneous defibrillation vs conventional cardiopulmonary resuscitation in out-of-hospital cardiac arrest: the LINC randomized trial. Jama 311:53-61.

4. Nehme Z, Nair R, Andrew E, Bernard S, Lijovic M, Villani M, Zoungas S, Smith K (2016) Effect of diabetes and prehospital blood glucose level on survival and recovery after out-of-hospital cardiac arrest. Critical care and resuscitation : journal of the Australasian Academy of Critical Care Medicine 18:69-77.

5. Parry M, Danielson K, Brennenstuhl S, Drennan IR, Morrison $\sqcup$ (2017) The association between diabetes status and survival following an out-of-hospital cardiac arrest: a retrospective cohort study. Resuscitation 113:21-26.

6. Shaw JE, Sicree RA, Zimmet PZ (2010) Global estimates of the prevalence of diabetes for 2010 and 2030. Diabetes Res Clin Pract 87:4-14.

7. Ro YS, Shin SD, Song KJ, Lee EJ, Lee YJ, Kim JY, Jang DB, Kim MJ, Kong SY (2015) Interaction effects between hypothermia and diabetes mellitus on survival outcomes after out-of-hospital cardiac arrest. Resuscitation 90:35-41.

8. Herlitz J, Ekstrom L, Wennerblom B, Axelsson A, Bang A, Holmberg S (1994) Risk indicators for, and symptoms associated with, death among patients hospitalized after out-of-hospital cardiac arrest. Coron Artery Dis 5:407-414.

9. Hallstrom AP, Cobb LA, Yu BH (1996) Influence of comorbidity on the outcome of patients treated for out-ofhospital ventricular fibrillation. Circulation 93:2019-2022.

10. Petursson P, Gudbjornsdottir S, Aune S, Svensson L, Oddby E, Sjoland H, Herlitz J (2008) Patients with a history of diabetes have a lower survival rate after in-hospital cardiac arrest. Resuscitation 76:37-42.

11. Larsson M, Thoren AB, Herlitz J (2005) A history of diabetes is associated with an adverse outcome among patients admitted to hospital alive after an out-of-hospital cardiac arrest. Resuscitation 66:303-307.

12. Povlsen JA, Lofgren B, Dalgas C, Birkler Rl, Johannsen M, Stottrup NB, Botker HE (2013) Protection against myocardial ischemia-reperfusion injury at onset of type 2 diabetes in Zucker diabetic fatty rats is associated with altered glucose oxidation. PLoS One 8:e64093.

13. La Bonte LR, Davis-Gorman G, Stahl GL, McDonagh PF (2008) Complement inhibition reduces injury in the type 2 diabetic heart following ischemia and reperfusion. Am J Phys Heart Circ Phys 294:H1282-H1290.

14. Ritter L, Davidson L, Henry M, Davis-Gorman G, Morrison H, Frye JB, Cohen Z, Chandler S, McDonagh P, Funk JL (2011) Exaggerated neutrophil-mediated reperfusion injury after ischemic stroke in a rodent model of type 2 diabetes. Microcirculation (New York, NY: 1994) 18:552-561.

15. Hokama JY, Ritter LS, Davis-Gorman G, Cimetta AD, Copeland JG, McDonagh PF (2000) Diabetes enhances leukocyte accumulation in the coronary microcirculation early in reperfusion following ischemia. J Diabetes Complicat 14:96-107.

16. Vognsen M, Fabian-Jessing BK, Secher N, Lofgren B, Dezfulian C, Andersen LW, Granfeldt A (2017) Contemporary animal models of cardiac arrest: a systematic review. Resuscitation 113:115-123.

17. Chen D, Wang MW (2005) Development and application of rodent models for type 2 diabetes. Diabetes Obes Metab 7:307-317.

18. Mullner M, Sterz F, Binder M, Schreiber W, Deimel A, Laggner AN (1997) Blood glucose concentration after cardiopulmonary resuscitation influences functional neurological recovery in human cardiac arrest survivors. Journal of cerebral blood flow and metabolism: official journal of the International Society of Cerebral Blood Flow and Metabolism 17:430-436.

19. Kim SH, Choi SP, Park KN, Lee SJ, Lee KW, Jeong TO, Youn CS (2014) Association of blood glucose at admission with outcomes in patients treated with therapeutic hypothermia after cardiac arrest. Am J Emerg Med 32:900-904.

20. Nurmi J, Boyd J, Anttalainen N, Westerbacka J, Kuisma M (2012) Early increase in blood glucose in patients resuscitated from out-of-hospital ventricular fibrillation predicts poor outcome. Diabetes Care 35:510-512

21. Molnar M, Bergquist M, Larsson A, Wiklund L, Lennmyr F (2014) Hyperglycaemia increases S100beta after short experimental cardiac arrest. Acta Anaesthesiol Scand 58:106-113.

22. MacDougall NJ, Muir KW (2011) Hyperglycaemia and infarct size in animal models of middle cerebral artery occlusion: systematic review and meta-analysis. Journal of cerebral blood flow and metabolism: official journal of the International Society of Cerebral Blood Flow and Metabolism 31:807-818.

23. Ye Y, Perez-Polo JR, Aguilar D, Birnbaum Y (2011) The potential effects of anti-diabetic medications on myocardial ischemia-reperfusion injury. Basic Res Cardiol 106:925-952.

24. Nolan JP, Soar J, Cariou A, Cronberg T, Moulaert VR, Deakin CD, Bottiger BW, Friberg H, Sunde K, Sandroni C (2015) European Resuscitation Council and European Society of Intensive Care Medicine 2015 guidelines for postresuscitation care. Intensive Care Med 41:2039-2056.

25. Kang J, Gong P, Ren YB, Gao DN, Ding QL (2013) Effect of beta-sodium aescinate on hypoxia-inducible factor1alpha expression in rat brain cortex after cardiopulmonary resuscitation. World J Emerg Med 4:63-68.

26. Huo TT, Zeng Y, Liu XN, Sun L, Han HZ, Chen HG, Lu ZH, Huang Y, Nie H, Dong HL, Xie KL, Xiong LZ (2014) Hydrogen-rich saline improves survival and neurological outcome after cardiac arrest and cardiopulmonary resuscitation in rats. Anesth Analg 119:368-380.

27. Qiu Y, Wu Y, Meng M, Luo M, Zhao H, Sun H, Gao S (2017) Rosuvastatin improves myocardial and neurological outcomes after asphyxial cardiac arrest and cardiopulmonary resuscitation in rats. Biomedicine \& Pharmacotherapy = Biomedecine \& Pharmacotherapie 87:503-508.

28. Zhang Y, Li CS, Wu CJ, Yang J, Hang CC (2015) Comparison of cerebral metabolism between pig ventricular fibrillation and asphyxial cardiac arrest models. Chin Med J 128:1643-1648. 
29. Foerster K, Benk C, Beyersdorf F, Cristina Schmitz H, Wittmann K, Taunyane I, Heilmann C, Trummer G (2018) Twenty minutes of normothermic cardiac arrest in a pig model: the role of short-term hypothermia for neurological outcome. Perfusion 33:270-277.

30. Ferdinandy P, Hausenloy DJ, Heusch G, Baxter GF, Schulz R (2014) Interaction of risk factors, comorbidities, and comedications with ischemia/reperfusion injury and cardioprotection by preconditioning, postconditioning, and remote conditioning. Pharmacol Rev 66:1142-1174.

31. Povlsen JA, Lofgren B, Rasmussen LE, Nielsen JM, Norregaard R, Kristiansen SB, Botker HE, Nielsen TT (2009) Cardioprotective effect of L-glutamate in obese type 2 diabetic Zucker fatty rats. Clin Exp Pharmacol Physiol 36: 892-898.

32. Wang $P$, Chatham JC (2004) Onset of diabetes in Zucker diabetic fatty (ZDF) rats leads to improved recovery of function after ischemia in the isolated perfused heart. Am J Phys Endocrinol Metab 286:E725-E736.

33. Adrie C, Laurent I, Monchi M, Cariou A, Dhainaou JF, Spaulding C (2004) Postresuscitation disease after cardiac arrest: a sepsis-like syndrome? Curr Opin Crit Care 10:208-212.

34. Kado S, Nagase T, Nagata N (1999) Circulating levels of interleukin-6, its soluble receptor and interleukin-6/ interleukin-6 receptor complexes in patients with type 2 diabetes mellitus. Acta Diabetol 36:67-72.

35. Arnalich F, Hernanz A, Lopez-Maderuelo D, Pena JM, Camacho J, Madero R, Vazquez JJ, Montiel C (2000) Enhanced acute-phase response and oxidative stress in older adults with type II diabetes. Hormone and metabolic research $=$ Hormon- und Stoffwechselforschung $=$ Hormones et metabolisme 32:407-412.

36. Pickup JC, Chusney GD, Thomas SM, Burt D (2000) Plasma interleukin-6, tumour necrosis factor alpha and blood cytokine production in type 2 diabetes. Life Sci 67:291-300.

37. Bro-Jeppesen J, Kjaergaard J, Wanscher M, Nielsen N, Friberg H, Bjerre M, Hassager C (2015) Systemic inflammatory response and potential prognostic implications after out-of-hospital cardiac arrest: a substudy of the target temperature management trial. Crit Care Med 43:1223-1232.

38. Bro-Jeppesen J, Johansson PI, Kjaergaard J, Wanscher M, Ostrowski SR, Bjerre M, Hassager C (2017) Level of systemic inflammation and endothelial injury is associated with cardiovascular dysfunction and vasopressor support in post-cardiac arrest patients. Resuscitation 121:179-186.

39. Opal SM, DePalo VA (2000) Anti-inflammatory cytokines. Chest 117:1162-1172.

40. Paradis NA, Martin GB, Rivers EP, Goetting MG, Appleton TJ, Feingold M, Nowak RM (1990) Coronary perfusion pressure and the return of spontaneous circulation in human cardiopulmonary resuscitation. Jama 263:1106-1113.

41. Laver S, Farrow C, Turner D, Nolan J (2004) Mode of death after admission to an intensive care unit following cardiac arrest. Intensive Care Med 30:2126-2128.

\section{Submit your manuscript to a SpringerOpen ${ }^{\circ}$ journal and benefit from:}

- Convenient online submission

- Rigorous peer review

- Open access: articles freely available online

High visibility within the field

- Retaining the copyright to your article

Submit your next manuscript at $>$ springeropen.com 